\title{
Confinement and Composition Effects on the Degradation Profile of Extruded PLA/PCL Nonwoven Fiber Blends
}

\author{
Kris M. Van de Voorde, ${ }^{a}$ LaShanda T. J. Korley, ${ }^{\text {a,b }}$ and Jonathan K. Pokorski*c,d \\ a Department of Materials Science and Engineering, University of Delaware Newark, Delaware, 19716, United States \\ ${ }^{\mathrm{b}}$ Department of Chemical Engineering, University of Delaware, Newark, Delaware, 19716, United States \\ ${ }^{c}$ Department of Nanoengineering, University of California San Diego, La Jolla, California, 92093, United States \\ ${ }^{\mathrm{d}}$ Institute for Materials Discovery and Design, University of California San Diego, La Jolla, California, 92093, United States \\ Ph: (858) 246-3183 E-mail: jpokorski@ucsd.edu \\ SUPPLEMENTAL INFORMATION
}




\section{Quantification of Fiber Isolation via Proton Nuclear Magnetic Resonance ( $\left.{ }^{1} \mathrm{H}-\mathrm{NMR}\right)$

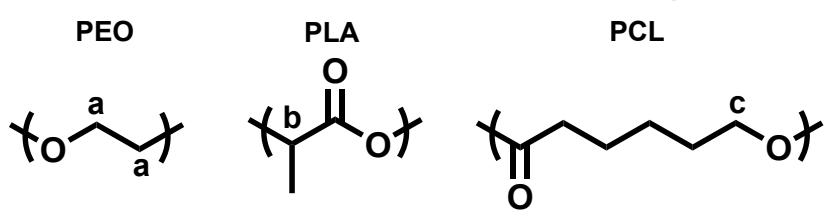

PEO protons associated with $a$ were integrated at a set value of 1.00 in the obtained ${ }^{1} \mathrm{H}$ NMR data. These protons were given a set value to determine the ratio of the integrated values of $c$ and $b$ to $a$. Here, $c$ corresponds to the two protons on the backbone of PCL, $b$ is associated with one proton on the PLA backbone, and the four protons on the backbone of PEO are correlated with a. Since each component has a different number of associated protons, Equation S1 and S2 were used to determine relative mole fractions of PCL to PEO and PLA to PEO, respectively, by utilizing an integral ratio.

$$
\begin{aligned}
& \frac{\frac{a \text { mol PEO }}{4}}{\frac{\text { e mol PCL }}{2}}=\frac{a}{2 c} \frac{\mathrm{mol} P E O}{\mathrm{~mol} P C L} \\
& \frac{\frac{a \text { mol PEO }}{4}}{\frac{\text { g mol PLA }}{1}}=\frac{a}{4 b} \frac{\mathrm{mol} \mathrm{PEO}}{\mathrm{mol} \mathrm{PLA}}
\end{aligned}
$$

The calculated mole fractions were converted to weight ratios using Equation S3 and S4 via the molar mass of the repeat unit of each component $(\mathrm{PCL}=114.14 \mathrm{~g} / \mathrm{mol} ; \mathrm{PCL}=72.06 \mathrm{~g} / \mathrm{mol}$; PEO $=44.05 \mathrm{~g} / \mathrm{mol})$.

$$
\begin{aligned}
& \left(\frac{a}{2 c}\right)\left(\frac{\mathrm{mol} \mathrm{PEO}}{\mathrm{mol} \mathrm{PCL}}\right)\left(\frac{1 \mathrm{~mol} P C L}{114.14 \mathrm{~g} P C L}\right)\left(\frac{44.05 \mathrm{~g} P E O}{1 \mathrm{~mol} \mathrm{PEO})}\right)=0.193 \frac{\mathrm{ag} P E O}{c g \text { PCL }} \\
& \left(\frac{a}{4 b}\right)\left(\frac{\mathrm{mol} P E O}{\text { mol PLA }}\right)\left(\frac{1 \mathrm{~mol} P L A}{72.03 \mathrm{~g} P L A}\right)\left(\frac{44.05 \mathrm{~g} P E O}{1 \mathrm{~mol} P E O)}\right)=0.153 \frac{a g \text { PEO }}{b g P L A}
\end{aligned}
$$

Since the peak for $a$ was set to an initial value of 1.00, the above expressions can be simplified to Equation S5 and S6:

$$
\begin{aligned}
& 0.193 \frac{a g P E O}{c g P C L}=0.193 \frac{1}{c} \frac{g P E O}{g P C L}=\frac{0.193 g \text { PEO }}{c \quad g P C L} \\
& 0.153 \frac{a g P E O}{b g P L A}=0.153 \frac{1}{b} \frac{g P E O}{g P L A}=\frac{0.153 g \text { PEO }}{b \quad g P L A}
\end{aligned}
$$

After an assumption of $1 \mathrm{~g}$ of PLA and $1 \mathrm{~g}$ of PCL was made, the weight of PEO could be calculated using Equation $\mathbf{S 7}$ and S8: 


$$
\begin{aligned}
& \left(\frac{0.193 g \text { PEO }}{c \quad g \text { PCL }}\right)(1 g \text { PCL })=\frac{0.193}{c} g \text { PEO } \\
& \left(\frac{0.153 g \text { PEO }}{b \quad g \text { PLA }}\right)(1 g \text { PLA })=\frac{0.153}{b} g \text { PEO }
\end{aligned}
$$

To determine the weight percentage (wt.\%) of the two polyester components, PLA and PCL, the assumption of $1 \mathrm{~g}$ of PLA and $1 \mathrm{~g}$ of PCL was again utilized for Equations S9 and S10.

$$
\begin{aligned}
& w t \% \text { of } P C L=\frac{1 g P C L}{1 g P C L+\frac{0.193}{c} g P E O} * 100 \%=\frac{1 g P C L}{\left(1+\frac{0.193}{c}\right) g \text { total }} * 100 \%=\frac{1}{1+\frac{0.193}{c}} * 100=\frac{1}{\frac{c+0.193}{c}} * 100 \\
& w t \% \text { of } P L A=\frac{1 g P L A}{1 g P L A+\frac{0.153}{b} g \text { PEO }} * 100 \%=\frac{1 g P L A}{\left(1+\frac{0.153}{b}\right) g \text { total }} * 100 \%=\frac{1}{1+\frac{0.153}{b}} * 100=\frac{1}{\frac{b+0.153}{b}} * 100
\end{aligned}
$$

Finally, the calculated weight percent of the two polyesters were combined in Equations S11. Here, a factor $x$ was implemented to account for the blend weight ratio of PLA to PCL. Specifically, the weight fraction of PLA is represented by $x(1,0.75,0.5,0.25$, and 0$)$.

$$
w t \% \text { of Polyester }=\left(x \frac{1}{\frac{c+0.193}{c}}+(1-x) \frac{1}{\frac{b+0.153}{b}}\right) * 100
$$

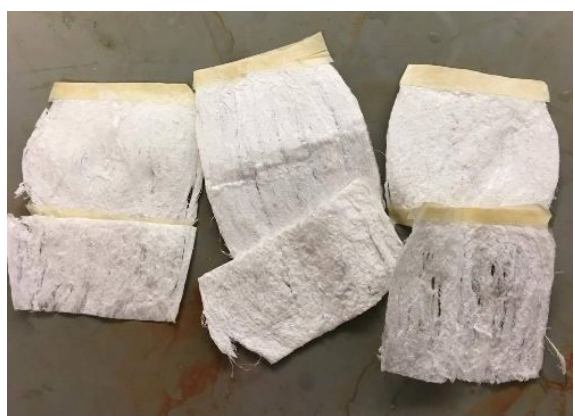

Figure S1. Photographs of isolated, non-woven fibers

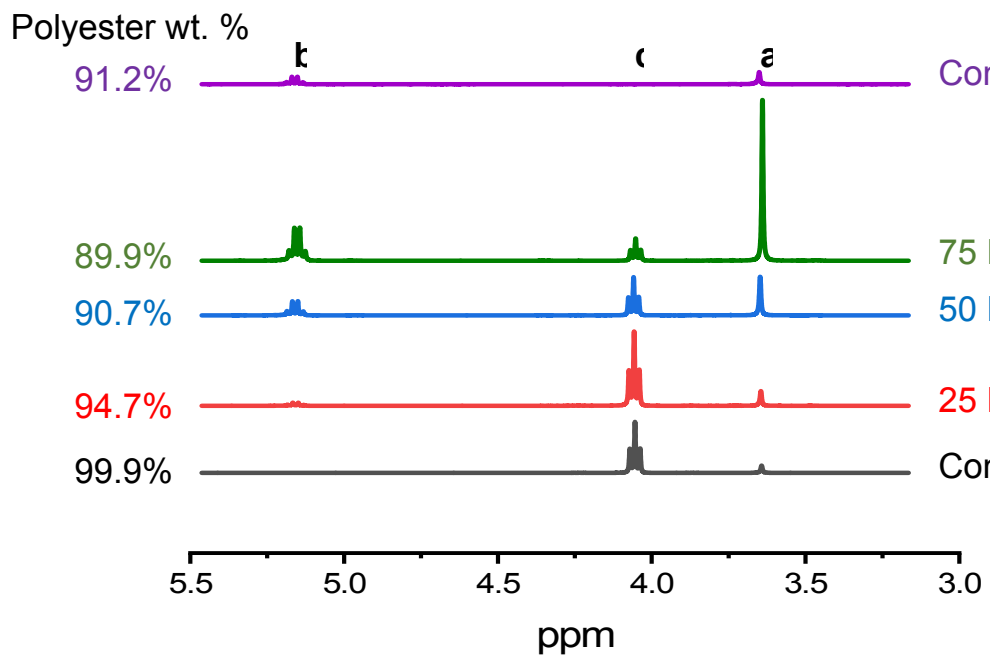

Figure S2. ${ }^{1} \mathrm{H}-\mathrm{NMR}$ analysis after the fiber isolation process. Relative integration values were calculated, and it was determined that the isolated PLA/PCL blended fibers were all $>89.9 \%$ polyester. 


\section{PLA/PCL Fiber Dimension}

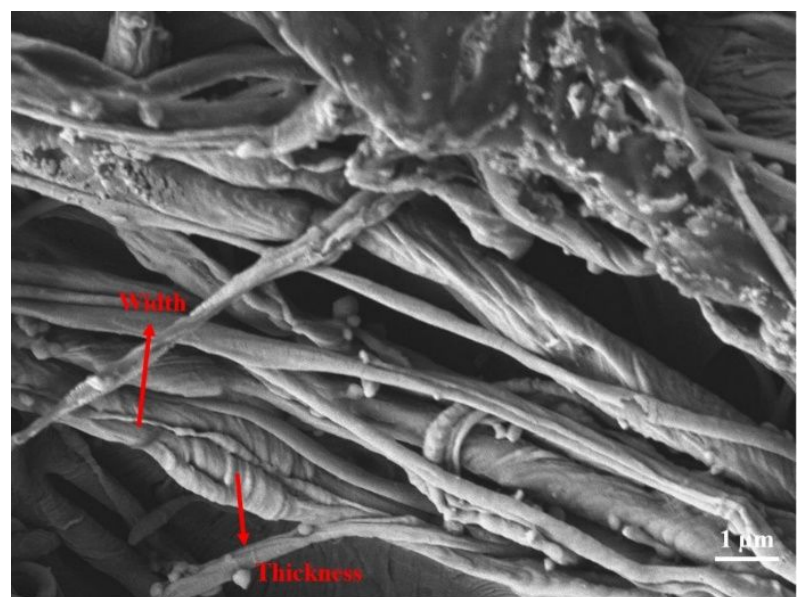

Figure S3. SEM micrograph of PCL fibers indicating the location of the width and thickness of the rectangular fibers.

Table S1. Dimensions of PLA and PCL fibers. The fibers obtained were $\sim 300 \mathrm{~nm}$ in width and $\sim 200 \mathrm{~nm}$ in thickness.

\begin{tabular}{|l|c|c|}
\hline System & Width $(\mu \mathrm{m})$ & Thickness $(\mu \mathrm{m})$ \\
\hline Control PLA & $0.23 \pm 0.1$ & $0.68 \pm 0.1$ \\
\hline 75 PLA/25 PCL & $0.34 \pm 0.1$ & $0.23 \pm 0.5$ \\
\hline 50 PLA/50 PCL & $0.31 \pm 0.1$ & $0.14 \pm 0.1$ \\
\hline 25 PLA/75 PCL & $0.32 \pm 0.1$ & $0.19 \pm 0.1$ \\
\hline Control PCL & $0.43 \pm 0.1$ & $0.22 \pm 0.5$ \\
\hline
\end{tabular}




\section{Determination of Blend Composition Throughout the in Vitro Degradation Study}

Similar to the fiber isolation quantifications, ${ }^{1} \mathrm{H}-\mathrm{NMR}$ was utilized to determine the weight fraction composition within the blended PLA/PCL nonwoven fibers exhibiting mass loss. Again, peaks associated with $b$ and $c$ protons were integrated. The PLA peak was integrated to a set value of 1.00. To calculate the weight fractions of PLA and PCL, a molar ratio (Equation S12) was initially defined to account for PLA having a single proton while PCL has two protons that were integrated.

$$
\frac{\frac{b \mathrm{~mol} \mathrm{PLA}}{1}}{\frac{\mathrm{cmol} \mathrm{PCL}}{2}}=\frac{2 b}{c} \frac{\mathrm{mol} \mathrm{PLA}}{\mathrm{mol} \mathrm{PCL}}
$$

This molar ratio was then converted to a weight ratio in Equation S13 by using the molar mass of the repeat units $(\mathrm{PCL}=114.14 \mathrm{~g} / \mathrm{mol} ; \mathrm{PCL}=72.06 \mathrm{~g} / \mathrm{mol})$.

$$
\left(\frac{2 b}{c}\right)\left(\frac{m o l ~ P L A}{m o l ~ P C L}\right)\left(\frac{1 m o l ~ P C L}{114.14 g P C L}\right)\left(\frac{72.06 g \text { PLA }}{1 m o l P L A)}\right)=\frac{1.26 b g P L A}{c \quad g P C L}
$$

Using a $b$ value of 1.00 , the equation was simplified to Equation S14.

$$
\frac{1.26 b g P L A}{c \quad g P C L}=1.26 \frac{1}{c} \frac{g P L A}{g P C L}=\frac{1.26 g P L A}{c g P C L}
$$

To further simplify the equation, an assumption of $1 \mathrm{~g}$ of PCL was made to give Equation S15.

$$
\left(\frac{1.26 g \text { PLA }}{c \quad g P C L}\right)(1 g P C L)=\frac{1.26}{c} g P L A
$$

Finally, this assumption was used again in Equation S16 to calculate the relative weight percent of the PCL component.

Table S2. 75 PLA/25 PCL ${ }^{1} \mathrm{H}-\mathrm{NMR}$ Integration.

$$
w t \% \text { of } P C L=\frac{1 g P C L}{1 g P C L+\frac{1.26}{c} g P L A} * 100 \%=\frac{1 g P C L}{\left(1+\frac{1.26}{c}\right) g \text { total }} * 100 \%=\frac{1}{1+\frac{1.26}{c}} * 100=\frac{1}{\frac{c+1.26}{c}} * 100
$$

75 PLA/25 PCL

\begin{tabular}{|c|c|c|}
\hline \multicolumn{3}{|c|}{75 PLA/25 PCL } \\
\hline & PCL Peak Integration & PCL relative amount \\
\hline Week 1 & 0.56 & $31 \%$ \\
\hline Week 2 & 0.56 & $31 \%$ \\
\hline Week 3 & 0.58 & $32 \%$ \\
\hline Week 4 & 0.60 & $32 \%$ \\
\hline
\end{tabular}


Table S3. 50 PLA/50 PCL ${ }^{1} \mathrm{H}-\mathrm{NMR}$ Integration.

\begin{tabular}{|c|c|c|}
\hline \multicolumn{3}{|c|}{ 50 PLA/50 PCL } \\
\hline & PCL Peak Integration & PCL relative amount \\
\hline Week 1 & 1.59 & $50 \%$ \\
\hline Week 2 & 2.30 & $65 \%$ \\
\hline Week 3 & 2.04 & $48 \%$ \\
\hline
\end{tabular}

Table S4. 25PLA/75 PCL ${ }^{1} \mathrm{H}-\mathrm{NMR}$ Integration.

\begin{tabular}{|}
\begin{tabular}{|c|c|c|}
\hline Week 4 & 5.05 & $80 \%$ \\
\hline \multicolumn{3}{|c|}{} \\
\hline \multicolumn{3}{|c|}{ 25 PLA/75 PCL } \\
\hline & PCL Peak Integration & PCL relative amount \\
\hline Week 1 & 3.74 & $75 \%$ \\
\hline Week 2 & 3.74 & $75 \%$ \\
\hline Week 3 & 11.85 & $90 \%$ \\
\hline Week 4 & 3.74 & $75 \%$ \\
\hline
\end{tabular}
\end{tabular}




\section{Differential Scanning Calorimetry}
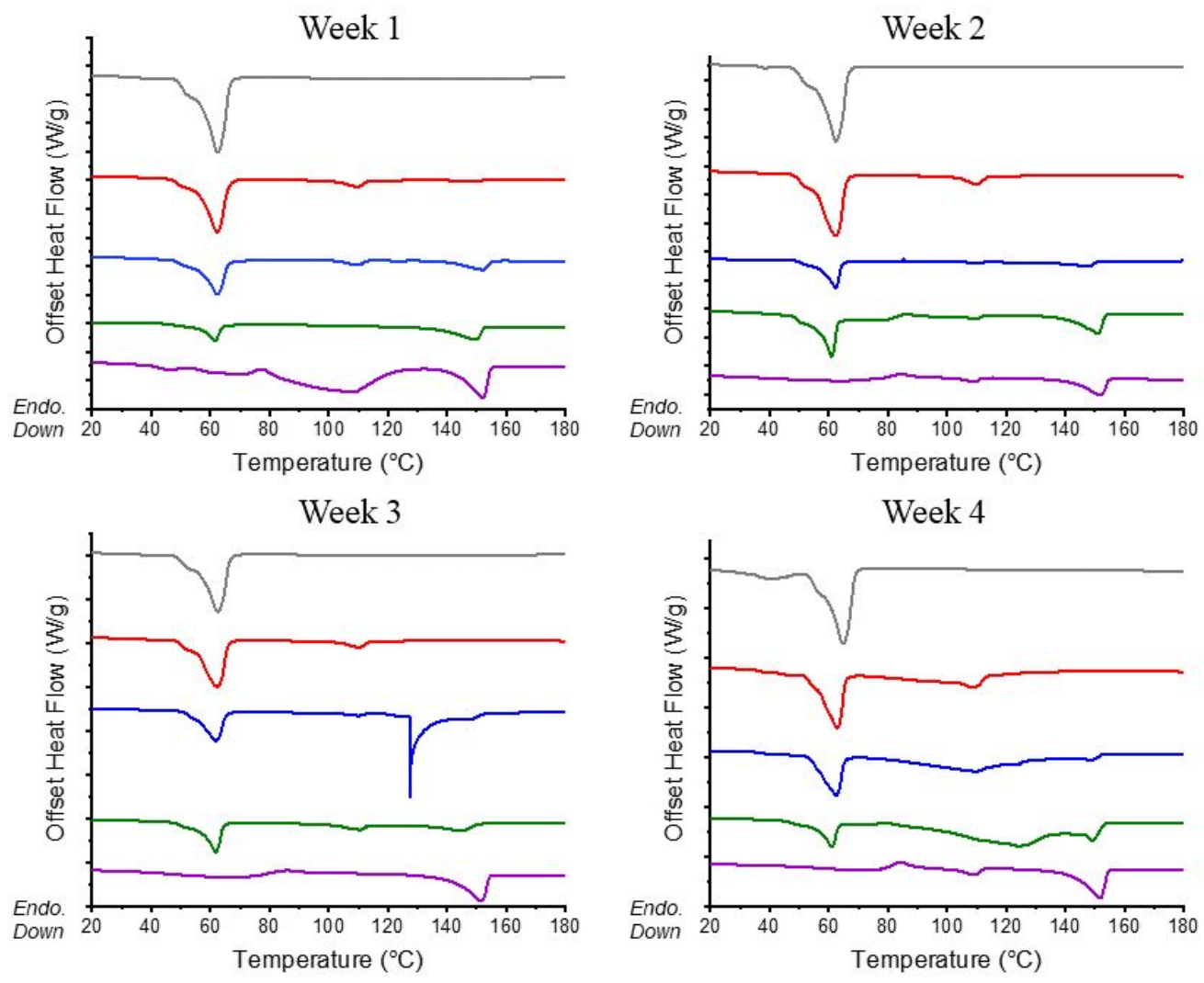

Figure S4. Thermograms from $1^{\text {st }}$ heating cycle. Purple $=$ control PLA, Green $=75$ PLA $/ 25$ PCL, Blue $=50$ PLA/50 PCL, Red= 25 PLA/75 PCL, Gray= control PCL 


\section{Wide-angle X-ray Scattering}

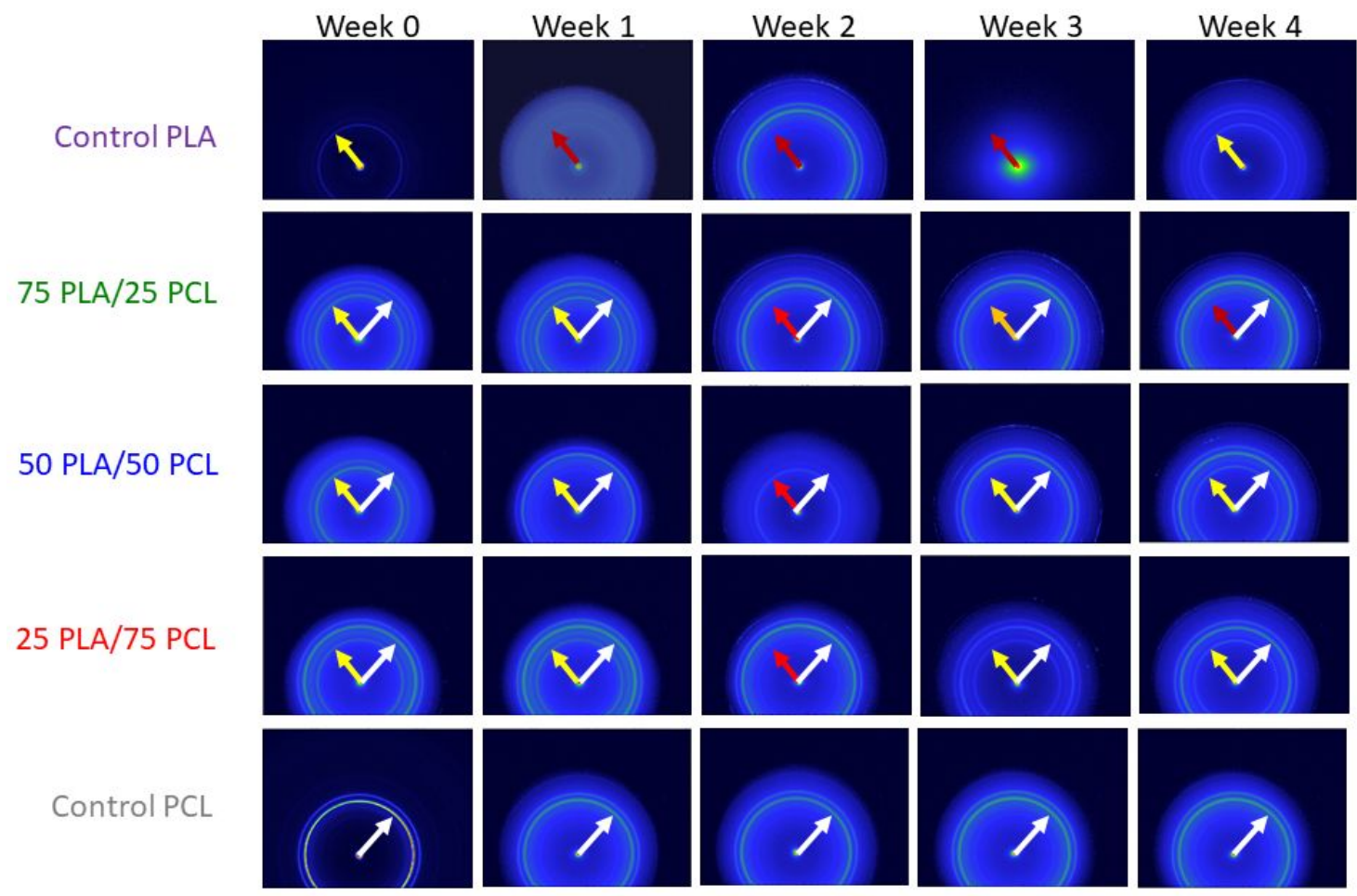

Figure S5. 2D WAXS Patterns for extruded PLA/PCL fibers. A yellow arrow indicates a PLA reflection. A white arrow indicates PCL reflection. The red arrow indicates absence of a PLA reflection.

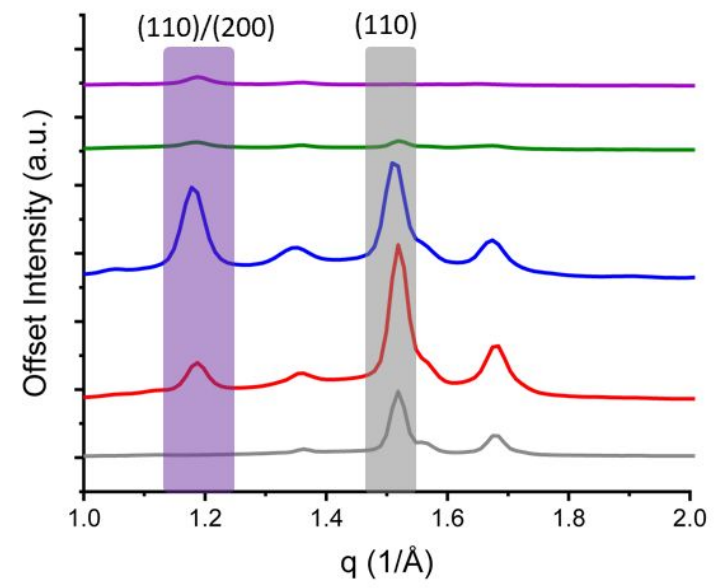

Figure S6. 1D WAXS Patterns for extruded PLA/PCL fibers prior to degradation. The purple region represents an isolated reflection that correlates to PLA, and the gray region corresponds to a reflection that is specific to PCL. Both PLA and PCL contribute to the additional reflections observed. 


\section{Tensile Testing}

To determine the void fraction, the apparent density of the nonwoven systems was calculated. This calculation was achieved by trimming samples into rectangles and calculating the volume and mass. Initially, the volume $(V)$ was measured using Equation S17.

$$
V=L * W * T
$$

The required measurements of the length $(L)$, width $(W)$, and thickness $(T)$ were obtained using calipers, and the mass $(M)$ was measured using an analytical balance. The volume and mass measurements were then utilized to calculate the density of the fibers $(\rho)$ (Equation S18).

$$
\rho=\frac{M}{V}
$$

Finally, the apparent density $(\varphi)$ of each sample was calculated by comparing the measured density to the density of the PLA $/$ PCL pellets $\left(\rho_{P C L}=1.15 \mathrm{~g} / \mathrm{mol} ; \rho_{P L A}=1.25 \mathrm{~g} / \mathrm{mol}\right)$ and the blend weight fractions $(w)$ were accounted for in Equation S19.

$$
\varphi_{\text {fiber }}=\frac{\left[\left(w_{P C L}\right)\left(\rho_{P C L}\right)+\left(w_{P L A}\right)\left(\rho_{P L A}\right)\right]-\rho}{\left[\left(w_{P C L}\right)\left(\rho_{P C L}\right)+\left(w_{P L A}\right)\left(\rho_{P L A}\right)\right]}
$$
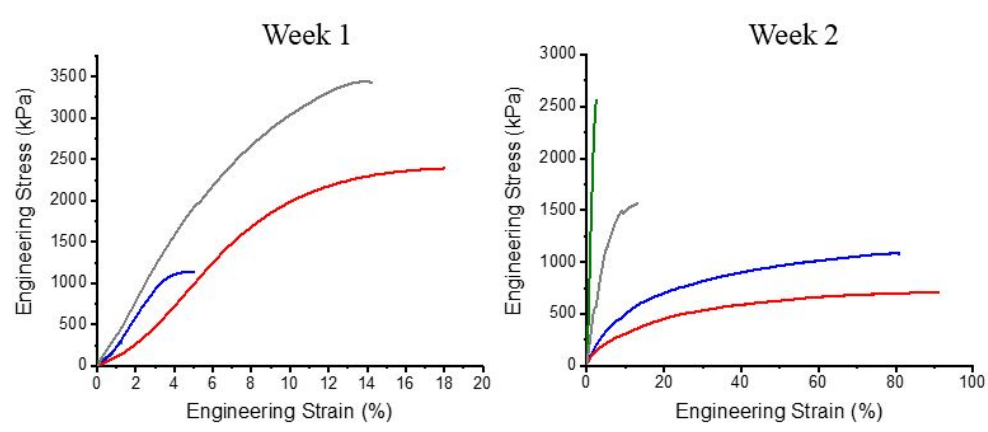

Week 3

Week 4
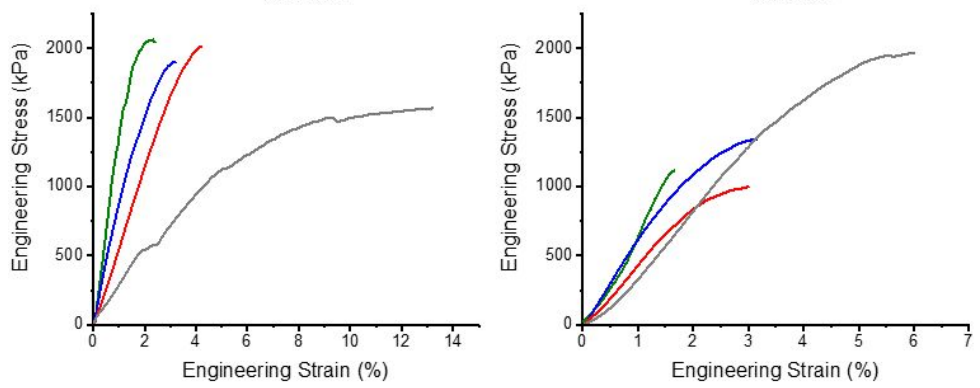

Figure S7. Stress-Strain Curves. Purple= control PLA, Green= 75 PLA/25 PCL, Blue= 50 PLA/50 PCL, Red= 25 PLA/75 PCL, Gray= control PCL 